\title{
Adsorption kinetics and equilibrium studies for removal of acid azo dyes by aniline formaldehyde condensate
}

\author{
Praisy Terangpi $^{1} \cdot$ Saswati Chakraborty ${ }^{2}$
}

Received: 28 January 2016/ Accepted: 28 November 2016/Published online: 21 December 2016

(c) The Author(s) 2016. This article is published with open access at Springerlink.com

\begin{abstract}
Adsorption of two acid dyes named Acid orange 8 (AO8) and Acid violet 7 (AV7) by amine based polymer aniline formaldehyde condensate (AFC) was studied. Adsorption of both dyes was favored at acidic pH. Electrostatic attraction between protonated amine group $\left(\mathrm{NH}_{3}{ }^{+}\right)$of AFC and anionic sulfonate group $\left(\mathrm{SO}_{3}{ }^{-}\right)$of dye molecule along with hydrogen bond formation and interaction between aromatic group of dye and AFC were responsible mechanisms for dye uptake. Isotherm of AO8 was Type I and followed Langmuir isotherm model. AV7 isotherm on AFC was of Type III and followed Freundlich model. Kinetics study showed that external mass transfer was the rate limiting step followed by intraparticle diffusion. Maximum adsorption capacities of AO8 and AV7 were observed as 164 and $68 \mathrm{mg} / \mathrm{g}$. AO8 dye being smaller in molecular size was adsorbed more due to higher diffusion rate and higher dye: AFC ratio, which enhanced the interaction between dye and polymer.
\end{abstract}

Keywords Acid azo dyes - Aniline formaldehyde condensate · Type I isotherm · Type III isotherm · External mass transfer - Dye:AFC ratio

Saswati Chakraborty saswati@iitg.ernet.in

1 Centre for the Environment, Indian Institute of Technology, Guwahati, Assam 7810239, India

2 Department of Civil Engineering, Indian Institute of Technology, Guwahati, Assam 781039, India

\section{Introduction}

The textile, leather, paint, cosmetics industries produce large quantities of wastewater containing dyes that are becoming a major environmental concern. It is estimated that $10-15 \%$ of dyes are wasted into the environment after their use in dyeing unit (Moussavi and Mahmoudi 2009). In India, an average mill producing $60 \times 10^{4} \mathrm{~m} /$ day of fabric is likely to discharge approximately 1.5 million L/day of effluent (CPCB 2000). In textile industries, acid dyes are largely used for high solubility, low cost and bright color and they remain unaffected in conventional treatment system (Moussavi and Mahmoudi 2009). The discharge of dye wastewater into the environment is aesthetically displeasing, impedes penetration of light and toxic to environment.

Due to good water solubility and poor biodegradability of acid dyes, it is difficult to eliminate them by conventional aerobic treatment (Robinson et al. 2001). Generation of large volumes of iron sludge and requirement of UV light and formation of byproducts hinder the application of advanced oxidation like Fenton and photo-Fenton process (Ahmad and Kumar 2010). Adsorption is the most versatile and widely used technology for dye removal because of low capital investment, less operating cost and high efficiency. Several low cost adsorbent materials have been developed such as cellulosic orange peel waste, banana pith, rice husk, clay, neem leaf powder, powdered activated sludge, activated carbon, gram husk, coal bottom ash, bagasse fly ash, deoiled soya, red mud, and sawdust (Gupta and Suhas 2009).

However, the major drawback of these materials is nonselective adsorption of acid dyes. Several amine based polymeric compounds were used for the removal of acid dyes. Amine based natural compounds like chitosan and 
crosslinked chitosan (Saha et al. 2005), ammonium chitosan derivative (Elwakeel et al. 2012) and synthetic polymers like MCM-41, polyaniline (PANI) were used for removals of sulfonated reactive and acid dyes (Qin et al. 2009; Donia et al. 2009; Mahanta et al. 2009; Ahmad and Kumar 2010).

Aniline formaldehyde condensate (AFC) is an amine based polymer, used for the removal of several heavy metals like $\mathrm{Cu}^{2+}, \mathrm{Cr}(\mathrm{VI})$ in our previous work (Kumar et al. 2007a, b, 2009). AFC is a low cost, short chain polymer with amine group throughout the chain length. To the best of our knowledge, no literature is available on azo dye removal by AFC polymer. Present study was carried out using Acid orange 8 (AO8) and Acid violet 7 (AV7) as model acid azo dyes to study adsorption kinetics, thermodynamics and equilibrium behavior on AFC. Both dyes are used in textile industry (Tunc et al. 2013; Mansour et al. 2007).

\section{Materials and methods}

\section{Materials}

Commercial grade aniline $\left(\mathrm{C}_{6} \mathrm{H}_{5} \mathrm{NH}_{2}\right)$ was purified by distilling over $\mathrm{KOH}$ pellets at boiling point temperature of aniline $\left(180^{\circ} \mathrm{C}\right)$. Formaldehyde was purchased from Spectrochem, India and was used as received. Column chromatographic silica gel (60-120 mesh) purchased from Merck was used as received.

AO8 and AV7 dyes were purchased from SigmaAldrich, Bangalore and used as received. Both dyes were in powder form and sulfonated monoazo dyes. The chemical formula of $\mathrm{AO} 8$ is $\mathrm{C}_{17} \mathrm{H}_{13} \mathrm{~N}_{2} \mathrm{NaO}_{4} \mathrm{~S}$ with molecular weight of $364.35 \mathrm{~g} / \mathrm{mol}$ and C.I. number 1557 . AV7 has molecular weight of $566.47 \mathrm{~g}$ and formula of $\mathrm{C}_{20} \mathrm{H}_{16} \mathrm{~N}_{4} \mathrm{Na}_{2} \mathrm{O}_{9} \mathrm{~S}_{2}$.

\section{Synthesis of polymers}

AFC was synthesized by reacting formaldehyde (HCHO) with aniline $\left(\mathrm{C}_{6} \mathrm{H}_{5} \mathrm{NH}_{2}\right)$. Detailed procedure is given in previous published literatures (Kumar et al. 2009). In a $100 \mathrm{~mL}$ beaker, $10 \mathrm{~mL}$ of $37 \%$ formaldehyde $(123 \mathrm{mmol})$ was added slowly to a mixture of $18.6 \mathrm{~g}$ of aniline (200 mmol) and $6 \mathrm{~mL}$ of concentrated $\mathrm{HCl}$ and kept in the water bath at $80{ }^{\circ} \mathrm{C}$ for $2 \mathrm{~h}$ with intermittent stirring. Then it was neutralized with $8 \mathrm{~mL}$ of $30 \% \mathrm{NaOH}$ and kept in the water bath for another $1 \mathrm{~h}$ at $60{ }^{\circ} \mathrm{C}$ temperature. Thereafter it was removed from the water bath and kept at room temperature for $12 \mathrm{~h}$, then washed for three to four times with warm water to remove residual aniline and formaldehyde and dried by applying vacuum in a vacuum desiccator. AFC synthesized was of yellow color resinous material. In $25 \mathrm{~mL}$ methanol $\left(\mathrm{CH}_{3} \mathrm{OH}\right)$ solution, $25-30 \mathrm{~g}$ resinous AFC polymer was dissolved at $40-45{ }^{\circ} \mathrm{C}$ with stirring. Experimentally, it was observed that maximum $25 \mathrm{~g}$ of silica could be added in methanol-AFC solution to completely soak the silica gel and permit mixing. After addition of $25 \mathrm{~g}$ silica gel in methanol-AFC mixture, manual stirring was applied for $5 \mathrm{~min}$. Then excess liquid was removed by filtering and AFC coated on silica gel was air dried for $6 \mathrm{~h}$. This AFC coated silica gel was used as the adsorbent for removal of acid dyes.

\section{Adsorption experiment}

Initial solution $\mathrm{pH}$, dose of adsorbent, temperature and initial concentration of dye were variable parameters for this study. All experiments were carried out with $250 \mathrm{~mL}$ of dye solution in $500 \mathrm{~mL}$ plastic bottles. Predetermined quantities of adsorbent were added to the bottles and initial solution $\mathrm{pH}$ was adjusted at desired value and mixing was achieved in the horizontal incubator shaker at $150 \mathrm{rpm}$ and $37{ }^{\circ} \mathrm{C}$ temperature. In $\mathrm{pH}$ study, initial $\mathrm{pH}$ of dye solution was adjusted using $0.1 / 1 \mathrm{~N} \mathrm{HCl} / \mathrm{NaOH}$ and known amount of adsorbent was added and kept for $12 \mathrm{~h}$ without $\mathrm{pH}$ control. Adsorbent dose was varied from 0.5 to $12 \mathrm{~g} / \mathrm{L}$ in a similar manner. In temperature study, temperature was varied from 10 to $50{ }^{\circ} \mathrm{C}$ with a known amount of adsorbent for $12 \mathrm{~h}$. For kinetic study, AO8 and AV7 solution with adsorbent was kept in horizontal shaker in different bottles and after regular time interval, each bottle was withdrawn from the shaker. After the experiment, adsorbent was separated from dye solution using centrifuge at $100 \mathrm{rpm}$ and residual concentration of dye and final $\mathrm{pH}$ was estimated. The amount of dye adsorbed on AFC was calculated based on the difference of dye concentrations in aqueous solution before and after adsorption experiment according to Eq. (1):

$q_{t}=\frac{\left(C_{0}-C_{t}\right) \times V}{m}$,

where, $q_{t}$ is the amount of dye adsorbed per unit weight of adsorbent $(\mathrm{mg} / \mathrm{g})$ at time $t, C_{0}$ and $C_{t}$ are the concentrations of dye $(\mathrm{mg} / \mathrm{L})$ at initial time and at time $t$, respectively, $V$ is the initial volume of dye solution (L) and $m$ is the mass of adsorbent $(\mathrm{g})$. When $t$ is equal to the equilibrium time, $C_{t}=C_{\mathrm{e}}, q_{t}=q_{\mathrm{e}}$, then the amount of dye adsorbed at equilibrium was calculated using the same Eq. (1). All experiments were done at least two times and average value of residual dye concentration was used in this study.

\section{Desorption study}

Desorption study was done using AO8/AV7 loaded AFC with different strengths of $\mathrm{NaOH}(0.05-0.5 \mathrm{~N})$ as desorbing 
agent. Desorbent volume was $50 \mathrm{~mL}$ in each case and desorption experiments were performed in a horizontal shaker at $150 \mathrm{rpm}$ for $6 \mathrm{~h}$. Then the samples were centrifuged and analyzed for dye concentration in desorbent solution. Desorption amount was calculated using Eq. (2):

Desorption $(\%)=\frac{\left(V_{\mathrm{des}} \times C_{\mathrm{des}}\right) \times 100}{\left(C_{0}-C_{\mathrm{e}}\right) V_{\mathrm{ads}}}$,

where, $V_{\text {des }}$ is the volume of desorbent used $(50 \mathrm{~mL}), C_{\mathrm{des}}$ is the final concentration of dye in solution after desorption $(\mathrm{mg} / \mathrm{L}), C_{\mathrm{e}}$ is equilibrium dye concentration after adsorption $(\mathrm{mg} / \mathrm{L}), C_{0}$ is the initial dye concentration before adsorption $(\mathrm{mg} / \mathrm{L})$ and $V_{\text {ads }}$ is the volume of dye solution used for adsorption experiment $(250 \mathrm{~mL})$.

\section{Analytical procedure}

Zero point charge of adsorbent was estimated using immersion technique as described by Fiol and Villaescusa (2009). Characterization of AFC was carried out using FTIR (Perkin Elmer, PE-RXI), FESEM (Hitachi 5500 FESEM), Particle size analyzer (Mastersizer 2000, Malvern) and BET surface area analysis (Autosorb-IQ MP).

The maximum wavelength for AO8 and AV7 were observed at 490 and $520 \mathrm{~nm}$, respectively, after scanning in UV-visible spectrophotometer from 400 to $800 \mathrm{~nm}$. Effect of solution $\mathrm{pH}$ on absorbance of dye was determined by varying initial $\mathrm{pH}(1-10)$ of AO8 solution of concentration $20 \mathrm{mg} / \mathrm{L}$. It was observed that within $\mathrm{pH}$ 6-7, maximum absorbance was achieved. All measurements of residual dye were carried out at this solution $\mathrm{pH}$. Calibration curve was prepared by dissolving known amount of dye powder in distilled water and adjusting solution $\mathrm{pH}$ to 3 and then absorbance was measured at $490 \mathrm{~nm}$ wavelength. AO8 dye followed Beer's law up to concentration of $25 \mathrm{mg} / \mathrm{L}$. The absorbance values were plotted against these known concentrations and linear absorbance curve was obtained with correlation coefficient of 0.99 . In a likely manner, the solution $\mathrm{pH}$ for maximum absorbance of AV7 was determined and it showed maximum absorbance at $\mathrm{pH}$ of $7-8$ and all analysis of AV7 dye were carried out at this $\mathrm{pH}$. AV7 showed linear absorbance up to concentration of $40 \mathrm{mg} / \mathrm{L}$.

\section{Results and discussion}

\section{Characterization of the polymers}

The particle size analysis of AFC-silica gel was evaluated volume wise for range of particle size. It was observed that mean particle diameter was $353 \mu \mathrm{m}$. FESEM image of AFC is shown in Fig. 1. The surface of AFC-silica gel shows that the surface was uneven. The point of zero charge $\left(\mathrm{pH}_{\mathrm{zpc}}\right)$ was determined from the change of $\mathrm{pH}$. It can be seen that $\mathrm{pH}$ change was minimum when initial $\mathrm{pH}$ was 5.5. The surface area of the adsorbent was determined using standard nitrogen adsorption porosimetric technique employing the BET method. BET specific surface area was $20.850 \mathrm{~m}^{2} / \mathrm{g} . \mathrm{N}_{2}$ adsorption isotherm on AFC is shown in Fig. 1. According to IUPAC classification, it followed Type-IV isotherm (Sing et al. 1985). Pore volume and pore radius of $\mathrm{AFC}$ were determined by employing the $\mathrm{BJH}$ method. Pore volume was $0.051 \mathrm{cc} / \mathrm{g}$ and pore diameter of $4.91 \mathrm{~nm}$, suggesting mesoporous adsorbent.

Fourier transform infrared spectrometer (FTIR) spectra of AFC polymer before and after adsorption of AO8 and AV7 are given in Fig. 2. The broad peak at 3400-3500 and $1550 \mathrm{~cm}^{-1}$ were the characteristics peaks for $\mathrm{NH}_{2}$ (Yang and Feng 2010). The peaks at 500 and $1000 \mathrm{~cm}^{-1}$ are due to $\mathrm{Si}-\mathrm{O}-\mathrm{Si}$ asymmetric stretching vibration (Donia et al. 2009). After adsorption of dyes, the band at 3400-3500 and $1550 \mathrm{~cm}^{-1}$ diminished.

\section{Effect of initial solution pH}

The optimum $\mathrm{pH}$ for dye uptake was determined and results are shown in Fig. 3. Acidic $\mathrm{pH}$ favored removals of both dyes. Maximum uptake was achieved at $\mathrm{pH}$ of 3 for AO8 and at pH of 2 for AV7 dye. The uncoated silica gel was used for the removal of AO8 and AV7 dye and it was observed that with $3 \mathrm{~g} / \mathrm{L}$ dose of silica gel, dye removal was only $7 \%$ for AV7 and $8 \%$ for AO8 dyes. This indicates that removal of dyes mainly occurred by polymer. Final $\mathrm{pH}$ is shown in Fig. 3. Change in $\mathrm{pH}$ followed similar trends for both dyes. Increase in $\mathrm{pH}$ was observed, when initial $\mathrm{pH}$ was less than 6 and decreased when initial $\mathrm{pH}$ was higher than 6 .

Acid dyes are anionic in nature and highly water soluble. They are effective for dyeing protein fibers like wool, nylon and silk (Donia et al. 2009). Acidic acid is used as a stimulator in dyeing process to adjust $\mathrm{pH}$ 3-4 (Chiou et al. 2004). Since AFC is more effective to remove acid dyes at lower $\mathrm{pH}$, no $\mathrm{pH}$ adjustment will be required for the treatment of acid dye containing industrial wastewater by AFC.

\section{Effect of temperature and thermodynamics}

Temperature was varied from 10 to $50{ }^{\circ} \mathrm{C}$ using initial dye concentration of $100 \mathrm{mg} / \mathrm{L}$ at initial $\mathrm{pH}$ of 3 . With increase in temperature, uptake of AO8 increased and AV7 decreased (Fig. 4).

Thermodynamic parameters like enthalpy change $\left(\Delta H^{\circ}\right)$ $(\mathrm{J} / \mathrm{mol})$ and entropy change $\left(\Delta S^{\circ}\right)(\mathrm{J} / \mathrm{mol} \mathrm{K})$ were 
Fig. 1 Characteristics of AFC polymer a FESEM image; $\mathbf{b} \mathrm{pH}$ for zero point charge; $\mathbf{c}$ BET isotherm

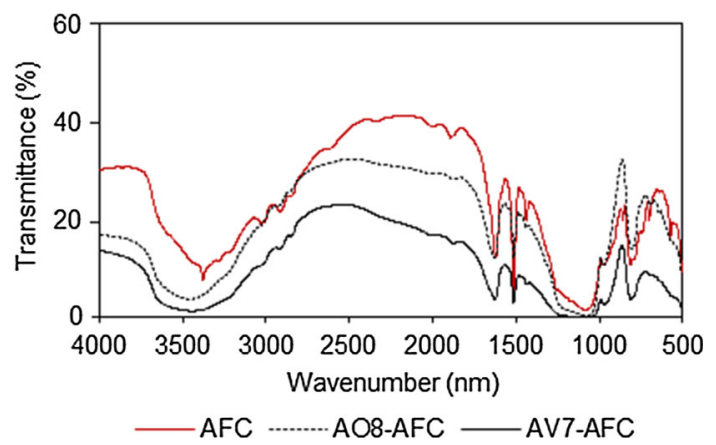

Fig. 2 FTIR spectra of AFC before and after adsorption of AO8 and AV7 dyes

evaluated using van't Hoff equation given below (Liu et al. 2015) and the plot is shown in Fig. 4b:

$\ln K_{\mathrm{L}}=\left(-\frac{\Delta H^{\circ}}{R T}\right)+\frac{\Delta S^{\circ}}{R}$,

where, $K_{\mathrm{L}}$ is distribution coefficient for adsorption given as $\left.\frac{q_{\mathrm{e}}}{C_{\mathrm{e}}} \mathrm{L} / \mathrm{g}\right) ; R$ is universal gas constant $(8.314 \mathrm{~J} / \mathrm{mol} \mathrm{K})$ and $T$ is absolute temperature $(\mathrm{K})$. Free energy change $\left(\Delta G^{\circ}\right)$ (J/mol) was calculated using Eq. (4) Liu et al. (2015): (b)

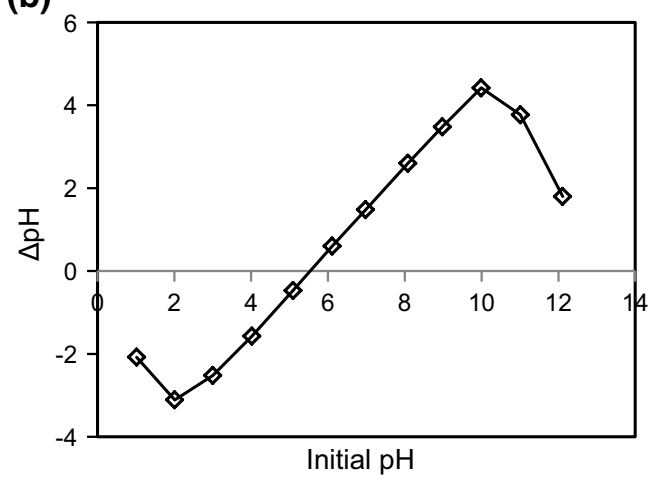

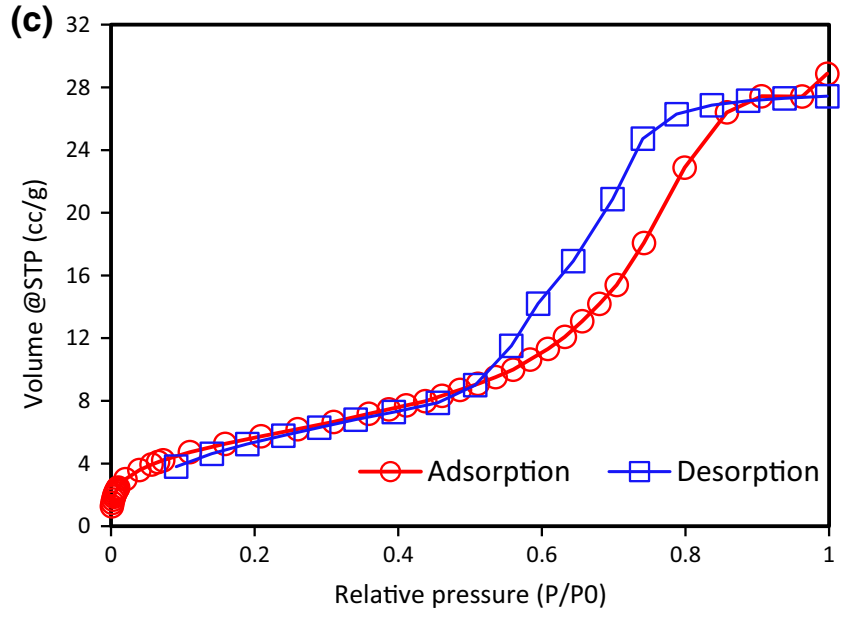

$\Delta G^{\circ}=\Delta H^{\circ}-T \Delta S^{\circ}$.

Values of thermodynamic parameters are given in Table 1. AO8 removal was endothermic and removal of AV7 was exothermic in nature. Enthalpy change was much higher for AO8 $(19.97 \mathrm{~kJ} / \mathrm{mol})$ than AV7 $(-5.45 \mathrm{~kJ} / \mathrm{mol})$. The heat of adsorption less than $20 \mathrm{~kJ} / \mathrm{mol}$ suggests that AV7 and AO8 adsorption processes were physical in nature. Entropy change was positive for AO8 and negative for AV7. Negative entropy change of AV7 dye indicated decreased disorder at solid-solution interface. Adsorption was spontaneous for AO8 from 10 to $50{ }^{\circ} \mathrm{C}$ and for AV7 from 10 to $40{ }^{\circ} \mathrm{C}$.

\section{Effect of adsorbent dose}

Dosage was varied from 0.5 to $12 \mathrm{~g} / \mathrm{L}$ using $100 \mathrm{mg} / \mathrm{L}$ of $\mathrm{AO} 8$ and AV7 dyes at initial $\mathrm{pH}$ of 3 . Initially with increase in adsorbent dose $(0.2-12 \mathrm{~g} / \mathrm{L})$, removal of AO8 increased and the increase was substantial when the dose was increased from 0.5 to $2 \mathrm{mg} / \mathrm{L}$ (Fig. 5). At adsorbent dose of $3.6 \mathrm{~g} / \mathrm{L}$, it achieved a plateau with $99 \%$ removal. In case of AV7 dye, removal increased up to a dose of $10 \mathrm{~g} / \mathrm{L}$ with maximum removal of $75 \%$. The maximum uptakes 
Fig. 3 Effect of solution $\mathrm{pH}$ on dye uptake and change in $\mathrm{pH}$ a $\mathrm{AO} 8$ and b $\mathrm{AV} 7$

Fig. 4 a Effect of temperature on dye uptake. b van't Hoff plot
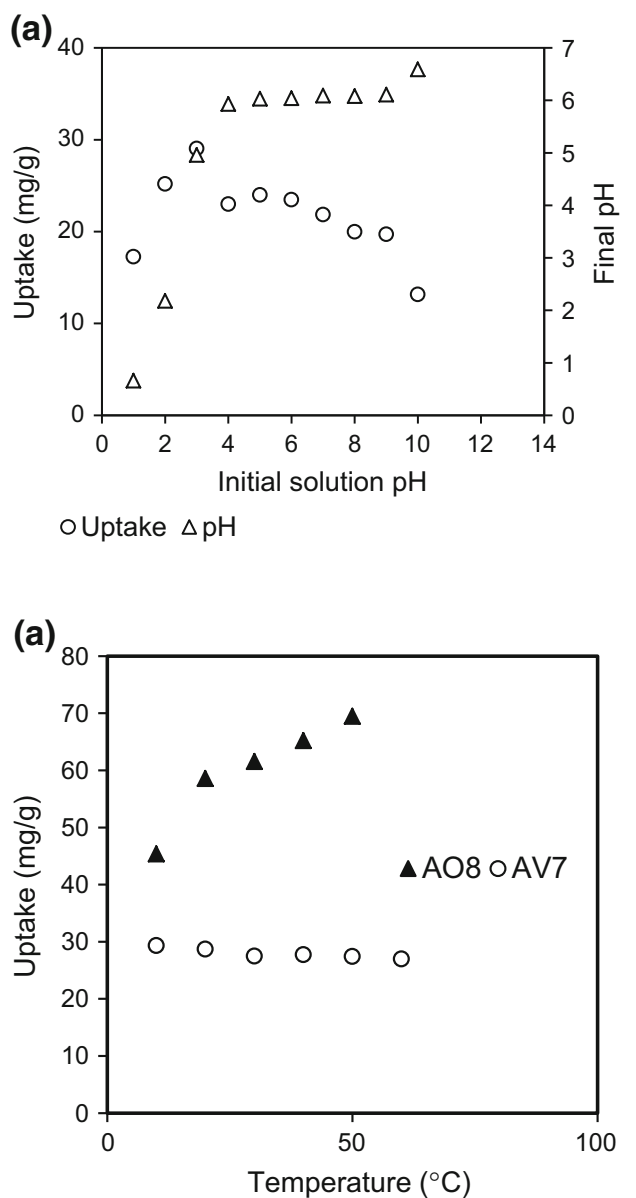

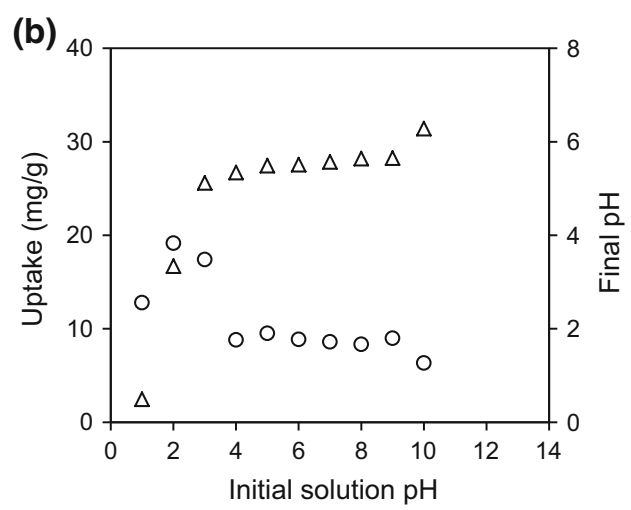

oUptake $\Delta \mathrm{pH}$

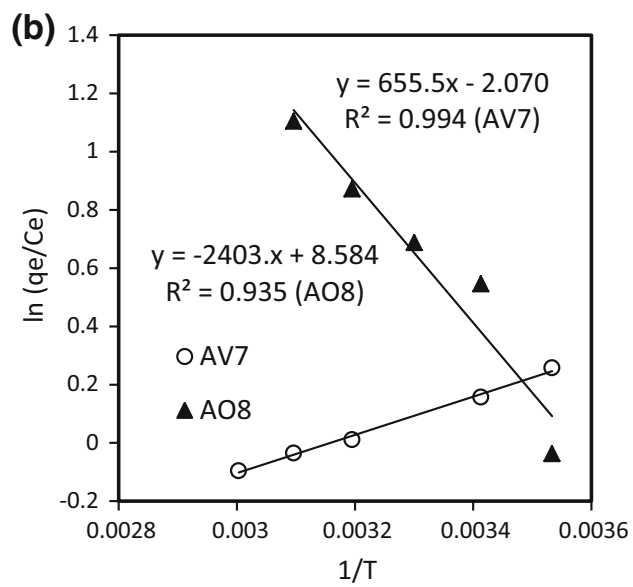

Table 1 Thermodynamic parameters for AO8 and AV7 dyes on AFC

\begin{tabular}{|c|c|c|c|c|c|c|c|c|}
\hline \multirow[t]{2}{*}{ Temperature $(\mathrm{K})$} & \multicolumn{4}{|l|}{ AO8 } & \multicolumn{4}{|l|}{ AV7 } \\
\hline & $\Delta H^{\circ}(\mathrm{kJ} / \mathrm{mol})$ & $\Delta S^{\circ}(\mathrm{J} / \mathrm{mol} \mathrm{K})$ & $\Delta G^{\circ}(\mathrm{kJ} / \mathrm{mol})$ & $T \Delta S^{\circ}(\mathrm{kJ} / \mathrm{mol})$ & $\Delta H^{\circ}(\mathrm{kJ} / \mathrm{mol})$ & $\Delta S^{\circ}(\mathrm{J} / \mathrm{mol} \mathrm{K})$ & $\Delta G^{\circ}(\mathrm{kJ} / \mathrm{mol})$ & $T \Delta S^{\circ}(\mathrm{kJ} / \mathrm{mol})$ \\
\hline 283 & 19.97 & 71.33 & -0.21 & 20.18 & -5.45 & -17.21 & -0.58 & -4.87 \\
\hline 293 & & & -0.92 & 20.90 & & & -0.40 & -5.04 \\
\hline 303 & & & -1.64 & 21.61 & & & -0.23 & -5.21 \\
\hline 313 & & & -2.35 & 22.32 & & & -0.063 & -5.38 \\
\hline 323 & & & -3.06 & 23.39 & & & 0.108 & -5.55 \\
\hline
\end{tabular}

were $164 \mathrm{mg} / \mathrm{g}(0.45 \mathrm{mmol} / \mathrm{g})$ for $\mathrm{AO} 8$ and $68 \mathrm{mg} / \mathrm{g}$ $(0.12 \mathrm{mmol} / \mathrm{g})$ for AV7.

\section{Adsorption isotherm}

Isotherm plots $\left(q_{\mathrm{e}}\right.$ vs $C_{\mathrm{e}}$ ) are shown in Fig. 6. Isotherm shapes were convex type for AO8 and concave type for AV7. Based on isotherm classification provided by Giles et al. (1974a), AO8 adsorption on AFC followed L2 type isotherms and AV7 followed S1 type isotherm. Based on another classification of IUPAC (Sing et al. 1985), AO8 isotherm was of Type I and AV7 was of Type III.
Several isotherm models were used to explain the behavior of dyes on AFC polymer. Langmuir, Freundlich and Tempkin models are given respectively in Eqs. (5-7) (Foo and Hameed 2010):

$q_{\mathrm{e}}=\frac{Q_{\mathrm{m}} b C_{\mathrm{e}}}{1+b C_{\mathrm{e}}}$,

$q_{\mathrm{e}}=K_{\mathrm{f}} C_{\mathrm{e}}^{1 / n}$,

$q_{\mathrm{e}}=\frac{R T}{\Delta Q} \ln A_{\mathrm{T}} C_{\mathrm{e}}$

where, $q_{e}$ is the amount of dye adsorbed at equilibrium $(\mathrm{mg} / \mathrm{g}) ; C_{e}$ is the aqueous phase dye concentration at 


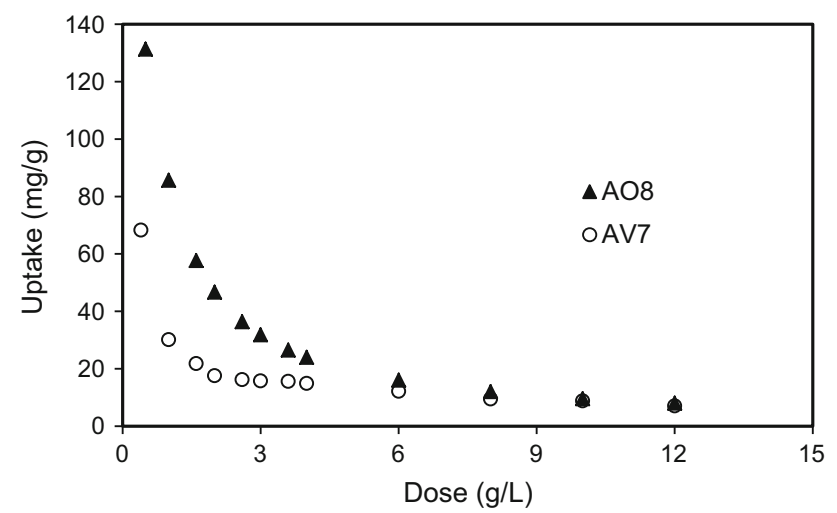

Fig. 5 Effect of AFC dose on dye uptake

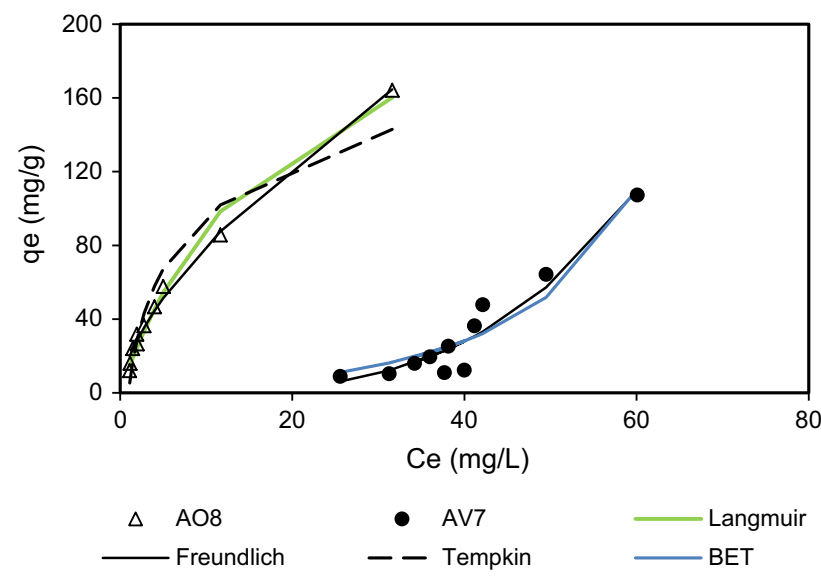

Fig. 6 Isotherm plots of AO8 and AV7 dyes on AFC

equilibrium (mg/L); $Q_{\mathrm{m}}$ is the adsorption capacity of the adsorbent $(\mathrm{mg} / \mathrm{g}), b$ is the affinity constant for adsorption $(\mathrm{L} / \mathrm{mg})$ in Langmuir model. $K_{\mathrm{f}}$ is the Freundlich capacity factor and $n$ is the index of heterogeneity. In Tempkin model (Eq. 7), $R$ is gas constant, $T$ is temperature (K), $\Delta Q$ is the variation of adsorption energy $(\mathrm{kJ} / \mathrm{mol})$ and $A_{\mathrm{T}}$ is Tempkin equilibrium constant $(\mathrm{L} / \mathrm{mg})$.

Isotherm parameters were determined using nonlinear regression and experimental isotherm data were compared with modeled data in a plot. The fitness of experimental and model data was verified from correlation coefficient $\left(R^{2}\right)$ and average relative error (ARE) (Eq. 8):

$\mathrm{ARE}=\frac{100}{n} \sum_{i=1}^{n}\left|\frac{\left(q_{\text {eexp }}-q_{\text {ecal }}\right)}{q_{\text {eexp }}}\right| i$,

where, $q_{\text {eexp }}$ and $q_{\text {ecal }}$ dye uptake values observed experimentally and calculated using isotherm model, respectively. Isotherm parameters are given in Table 2. In Fig. 6, experimental and modeled isotherm plots are shown for both dyes. For AO8 dye, both Langmuir and Freundlich models provided $R^{2}$ value of 0.99 and lowest ARE value was obtained with Langmuir model. Figure 6 also shows that experimental data followed Langmuir model (green line) pretty well. Hinz (2001) suggested that L type isotherm can be described by Langmuir model. It is evident that AO8 adsorption on AFC can be best described by Langmuir model with maximum monolayer uptake of $252 \mathrm{mg} / \mathrm{g}$ and affinity constant of $0.054 \mathrm{~L} / \mathrm{mg}$.

Adsorption isotherm of AV7 dye showed an upward curvature. Langmuir and Tempkin models were unable to fit experimental data with low $R^{2}$ value and high ARE value (Table 2). Previous researchers observed that for this type of isotherm, Freundlich, BET models fit experimental data better (Hinz 2001; Girods et al. 2009). BET model is given in Eq. (9):

$$
q_{\mathrm{e}}=\frac{Q_{\mathrm{m}} B C_{\mathrm{e}}}{\left(C_{\mathrm{s}}-C_{\mathrm{e}}\right)\left[1+(B-1)\left(\frac{C_{\mathrm{e}}}{C_{\mathrm{s}}}\right)\right]},
$$

where, $Q_{\mathrm{m}}$ is the amount adsorbed in a complete monolayer, $B$ is equilibrium constant and $C_{\mathrm{s}}$ is the saturation concentration of adsorbate in water. Figure 6 shows that experimental isotherm data of AV7 dye followed both BET and Freundlich models. However, Table 2 shows that Freundlich model provided higher $R^{2}$ and lower ARE value than BET model. Also, BET isotherm provided exceptionally high $Q_{\mathrm{m}}$ value, than observed in this study. Since, AV7 adsorption on AFC followed Freundlich isotherm, the adsorption was heterogeneous and multilayer. The slope in Freundlich model, $1 / n$, was higher than 1 , suggesting cooperative adsorption of AV7 adsorption on AFC. Giles et al. (1974b) reported that $S$ type isotherm many times follow cooperative adsorption, where adsorbate molecules tending to be adsorbed in rows or clusters.

\section{Effect of initial dye concentration}

Dye uptakes with time at varying initial concentrations $(20-150 \mathrm{mg} / \mathrm{L})$ for AO8 and AV7 are given in Fig. 7. At lower adsorbate concentration ( 20 and $50 \mathrm{mg} / \mathrm{L}$ ) both dyes had shown comparable uptakes $(6$ and $5 \mathrm{mg} / \mathrm{g}$ at $20 \mathrm{mg} / \mathrm{L}$ and 14.6 and $14.2 \mathrm{mg} / \mathrm{g}$ at $50 \mathrm{mg} / \mathrm{L}$ for AO8 and AV7, respectively). With increase in initial dye concentration, uptakes increased and uptake was much higher for $\mathrm{AO} 8$ $(46 \mathrm{mg} / \mathrm{g})$ than AV7 $(25 \mathrm{mg} / \mathrm{g})$ at initial dye concentration of $150 \mathrm{mg} / \mathrm{L}$. Figure 7 shows that equilibrium time was $180 \mathrm{~min}$ for AO8 concentration of $20-50 \mathrm{mg} / \mathrm{L}$ and increased to $600 \mathrm{~min}$, at AO8 concentrations of 100 and $150 \mathrm{mg} / \mathrm{L}$. With AV7, equilibrium time was longer, 660-720 min at $20-50 \mathrm{mg} / \mathrm{L}$ concentration and increased to $1020 \mathrm{~min}$ at concentrations of 100 and $150 \mathrm{mg} / \mathrm{L}$.

\section{Adsorption kinetics}

Kinetic data of AO8 and AV7 on AFC (Fig. 7) were analyzed using intraparticle diffusion model (Weber and Morris 1963) (Eq. 10): 
Table 2 Estimated isotherm parameters for adsorption of AO8 and AV7 dyes on AFC polymer at pH 3 and $37^{\circ} \mathrm{C}$

\begin{tabular}{|c|c|c|c|}
\hline Isotherm model & Parameters & $\mathrm{AO} 8$ & AV7 \\
\hline \multirow[t]{4}{*}{ Langmuir } & $Q_{\mathrm{m}}(\mathrm{mg} / \mathrm{g})$ & 252.8 & 0.0002 \\
\hline & $b(\mathrm{~L} / \mathrm{mg})$ & 0.054 & 4392 \\
\hline & $R^{2}$ & 0.99 & 0.92 \\
\hline & ARE & 11.02 & 95.94 \\
\hline \multirow[t]{4}{*}{ Freundlich } & $K_{\mathrm{f}}$ & 18.58 & 0.0001 \\
\hline & $1 / n$ & 1.58 & 3.37 \\
\hline & $R^{2}$ & 0.99 & 0.96 \\
\hline & ARE & 13.33 & 8.43 \\
\hline \multirow[t]{4}{*}{ Tempkin } & $A_{\mathrm{T}}(\mathrm{L} / \mathrm{mg})$ & 1.02 & 0.031 \\
\hline & $\Delta Q(\mathrm{~kJ} / \mathrm{mol})$ & 61.32 & 16.24 \\
\hline & $R^{2}$ & 0.97 & 0.93 \\
\hline & ARE & 25.34 & 103.35 \\
\hline \multirow[t]{5}{*}{ BET } & $Q_{\mathrm{m}}(\mathrm{mg} / \mathrm{g})$ & - & 181,971 \\
\hline & $C_{\mathrm{s}}(\mathrm{mg} / \mathrm{L})$ & - & 92.60 \\
\hline & $B(\mathrm{~L} / \mathrm{mg})$ & - & 0.0001 \\
\hline & $R^{2}$ & - & 0.95 \\
\hline & ARE & - & 40.16 \\
\hline
\end{tabular}

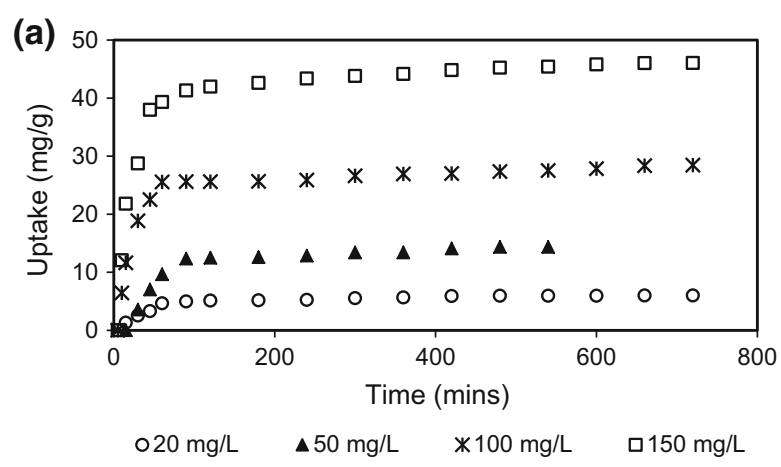

(b)

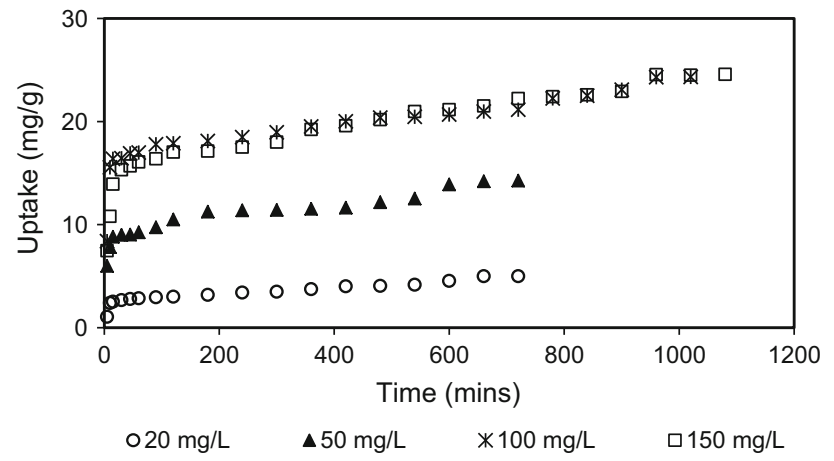

Fig. 7 Uptake of dyes with time a AO8 and b AV7

$q_{t}=k_{\mathrm{i}} t^{0.5}+y$,

where $q_{t}(\mathrm{mg} / \mathrm{g})$ is the amount of dye adsorbed on AFC at different times $t(\mathrm{~min}), k_{\mathrm{i}}$ is the rate of intraparticle diffusion $\left(\mathrm{mg} / \mathrm{L} \min ^{0.5}\right)$ and intercept, $y$ is the thickness of the boundary layer. Intraparticle diffusion becomes the sole rate limiting step in adsorption, when intercept becomes zero. Plots are shown in Fig. 8. It is evident that plots were straight lines but did not pass through origin, suggesting AO8 and AV7 adsorption on AFC involved intraparticle diffusion, but it was not sole rate controlling step.

The slope of the plot of the linear part of the $q_{t}$ against $t^{0.5}$ plot (here taken between 15 and 200-240 min) gives the values of diffusion rates $\left(k_{\mathrm{i}}\right)$. Values of diffusion rates $\left(k_{\mathrm{i}}\right)$ are given in Table 3. Regression analysis showed initial internal adsorption rate with dye concentration followed by the following relation.

$k_{\mathrm{i}}=(-2.60) C_{0}^{0.012}(\mathrm{AO} 8)$,

$k_{\mathrm{i}}=(-2.73) C_{0}^{0.008}(\mathrm{AV} 7)$.

Reichenberg (1953) model was used to understand the role of external mass transfer/film diffusion on adsorption of acid dyes by AFC (Eq. 13):

$F=1-\frac{6}{\pi^{2}} \sum_{n=1}^{\infty} \frac{1}{n^{2}} \exp \left(\frac{-n^{2} D_{\mathrm{s}} \pi^{2} t}{R^{2}}\right)$,

where, $F$ is fractional uptake at any time $t(\min )$ and $F=\frac{q_{t}}{q_{\mathrm{e}}}, q_{t}$ and $q_{\mathrm{e}}$ are dye uptakes at time $\mathrm{t}$ and equilibrium, respectively, $D_{\mathrm{s}}$ is the effective diffusion coefficient $\left(\mathrm{cm}^{2} /\right.$ $\mathrm{min}), \mathrm{n}$ is an integer that defines the infinite series solution. In Eq. (13), $\frac{\pi^{2} D_{\mathrm{s}}}{R^{2}}$ is substituted by $B$ and shown in Eq. (14) (Reichenberg 1953): 
Fig. 8 Intraparticle diffusion plots for AO8 and AV7 dyes on AFC

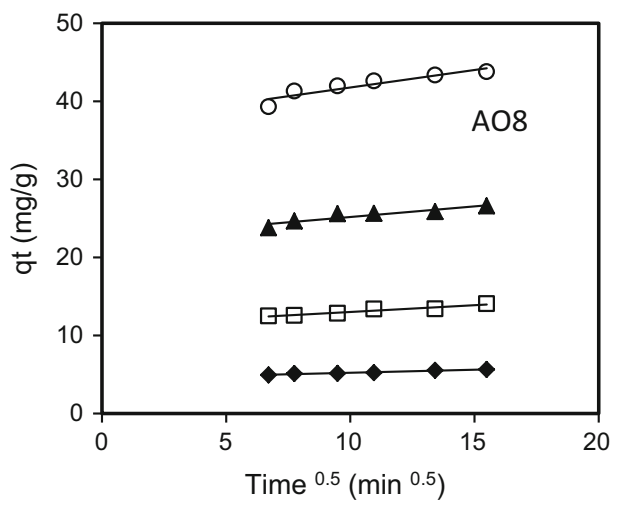

Table 3 Kinetic parameters of AO8 and AV7 dyes adsorption by AFC polymer

\begin{tabular}{lllll}
\hline Initial dye $(\mathrm{mg} / \mathrm{L})$ & \multicolumn{2}{l}{ Intraparticle diffusion } & \\
\cline { 2 - 5 } & $\mathrm{AO8}$ & $k_{\mathrm{i}}\left(\mathrm{mg} / \mathrm{min}^{0.5}\right)$ & $\mathrm{AV7}$ & $R^{2}$ \\
\cline { 2 - 5 } & $R^{2}$ & 0.078 & 0.97 & 0.068 \\
\hline 50 & 0.97 & 0.174 & 0.96 & 0.106 \\
100 & 0.94 & 0.272 & 0.91 & 0.178 \\
150 & 0.86 & 0.449 & 0.94 & 0.201 \\
\hline
\end{tabular}

$F=1-\frac{6}{\pi^{2}} \sum_{n=1}^{\infty} \frac{1}{n^{2}} \exp \left(n^{2} B t\right)$

The values of $B t$ for each value of $F$ was calculated as proposed by Reichenberg (1953) and given below:

$F$ values $<0.85$,

$$
B t=6.28318-3.2899 F-6.28318(1-1.0470 F)^{\frac{1}{2}},
$$

$F$ values $>0.85, \quad B t=-0.4997-\ln (1-F)$.

The plots of $B t$ vs. $t$ (Boyd's plot) are shown in Fig. 9 for both dyes. The plots were nonlinear and did not pass through origin for both AO8 and AV7, suggesting that during initial 90-120 min, external resistance was strong and external mass transfer was controlling step in adsorption, though diffusion was also important in AO8 and AV7 adsorptions. Mohan and Singh (2002) cited that low concentration of adsorbate, inadequate mixing, high affinity between adsorbate and adsorbent as reasons for film diffusion to be controlling step in adsorption. The lower initial dye concentration was probably responsible for adsorption controlled by external mass transfer/film diffusion.

\section{Desorption and reuse}

Desorption of dyes from AFC surface was studied using varying strength of $\mathrm{NaOH}$ solution $(0.0 .5-0.5 \mathrm{~N})$.
Maximum desorption was achieved at $\mathrm{NaOH}$ strength of $0.1 \mathrm{~N}$ for AO8 and AV7. However, desorption of AV7 was much higher (88\%) than AO8 (49\%) as shown in Fig. 10.

\section{Cost analysis of AFC coated silica gel with chitosan}

In a single batch of AFC synthesis, yield of AFC-silica is 30-33 g and total cost of AFC-silica (based on raw materials) is Rs. 169/30 g, with Rs. 5.63/g. Price of chitosan varies in a wide-range from Rs. $700-1390 / 25 \mathrm{~g}$ with Rs. $28-55 / \mathrm{g}$. Cost of chitosan as an adsorbent is many folds higher than AFC-silica, which may be useful for the treatment of large volume of dye containing wastewater at a lower cost.

Dye removal capacity of AFC-silica was compared with published results using an acid dye, Methyl orange (MO) and results are given in Table 4. It can be seen that $\mathrm{Zr}$ (IV) immobilized chitosan/bentonite composite had four times higher uptake of MO dye than AFC-silica. Another Chitosan/alumina composite showed twofold higher uptake of MO dye than AFC-silica in similar experimental condition. Cost analysis showed simple chitosan was higher than AFC-silica by more than fivefold, suggesting applicability of AFC-silica.

\section{Dye removal mechanism by AFC polymer}

In the aqueous solution, the sulfonate groups of the acid dyes $\left(\mathrm{R}-\mathrm{SO}_{3} \mathrm{Na}\right)$ were dissociated and converted to anionic 
Fig. 9 Boyd's plots for AO8 and AV7 dyes on AFC

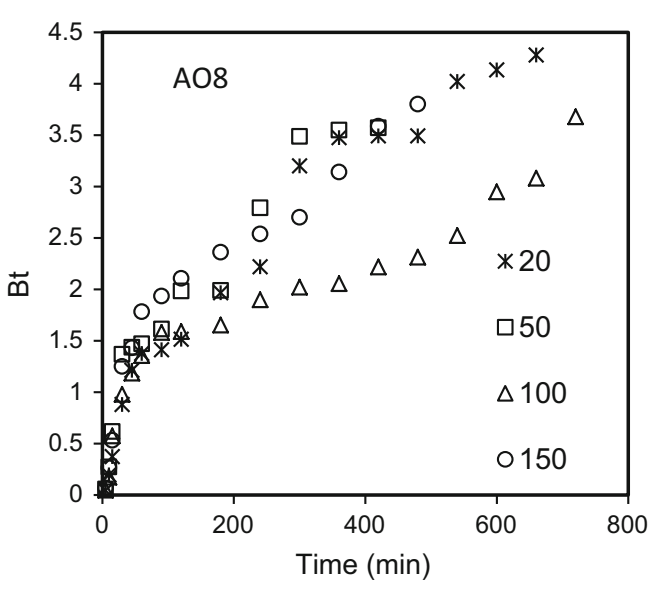

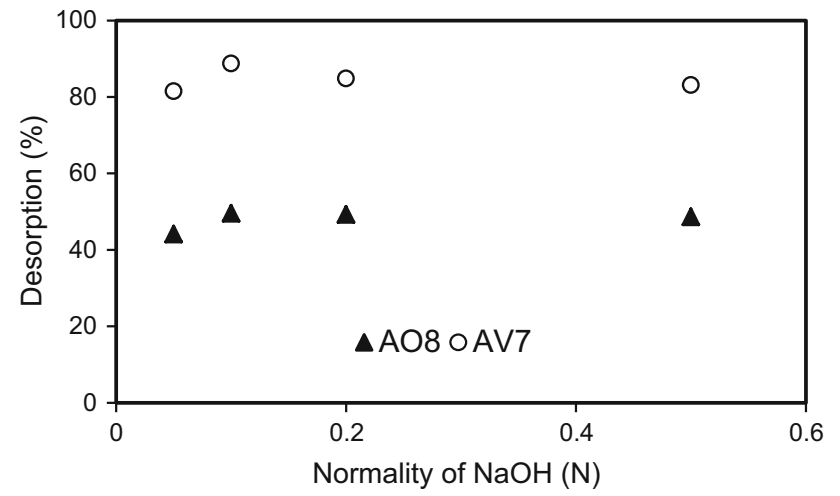

Fig. 10 Desorption of dyes from AFC

dye ions $\left(\mathrm{R}_{-} \mathrm{SO}_{3}{ }^{-}\right)$. At lower $\mathrm{pH}$, many hydrogen ions were available in solution and amine group $\left(-\mathrm{NH}_{2}\right)$ of AFC accepted protons and remained in protonated form $\left(\mathrm{NH}_{3}{ }^{+}\right)$ and solution $\mathrm{pH}$ increased. Electrostatic attraction between amine $\left(\mathrm{NH}_{3}{ }^{+}\right)$and anionic dye molecule $\left(\mathrm{R}_{-} \mathrm{SO}_{3}{ }^{-}\right)$was responsible for higher uptakes of $\mathrm{AV7}$ and $\mathrm{AO} 8$ at strong acidic $\mathrm{pH}(2-3)$. At neutral and alkaline $\mathrm{pH}$, AFC surface was in deprotonated form $\left(-\mathrm{NH}_{2}\right)$ and electrostatic attraction and dye uptake decreased. Similar mechanism for acid dye uptake by amine group of chitosan and crosslinked chitosan were suggested by previous researchers (Liu et al. 2015; Elwakeel et al. 2016a, b). $\mathrm{pH}_{\mathrm{zpc}}$ of $\mathrm{AFC}$ was observed as 5.5, suggesting that above this $\mathrm{pH}$ value, AFC surface had negative charge and Fig. 3 shows that some adsorption of dyes still occurred within $\mathrm{pH}$ range of 5.5-10. Electrostatic attraction could not be responsible for dye removals above $\mathrm{pH}$ 5.5. Hydrogen bond formation between nitrogen of amine group of polymers and $\mathrm{OH}$ group of dye, hydrophobic interaction between aromatic group of dye and polymers are other possible mechanisms of AO8 and AV7 removal from solution. Dye removal mechanism by AFC is shown in Fig. 11.

Maximum dye uptakes were different for both the dyes, with AO8 maximum uptake was $164 \mathrm{mg} / \mathrm{g}(0.45 \mathrm{~mol} / \mathrm{g})$ and AV7 maximum uptake observed was $68 \mathrm{mg} / \mathrm{g}$ $(0.12 \mathrm{mmol} / \mathrm{g})$. Structure of dye was responsible for difference in uptake. AO8 dye was monovalent with single $\mathrm{SO}_{3}{ }^{-}$group and AV7 dye was divalent (two $\mathrm{SO}_{3}{ }^{-}$) (Fig. 10). AO8 was smaller than AV7 in molecular size and this helped in higher diffusion of AO8 dye molecules. Higher diffusion rates $\left(k_{\mathrm{i}}\right)$ in Table 3 also confirm this. Further, when same adsorbent dose and same initial dye concentration was used, dye:AFC ratio was higher for AO8 than AV7. At AFC dose of $1 \mathrm{~g} / \mathrm{L}$ and initial dye concentration of $100 \mathrm{mg} / \mathrm{L}, \mathrm{AO} 8 \mathrm{AFC}$ ratio was $0.27 \mathrm{mmol} / \mathrm{g}$ and AV7:AFC ratio was $0.17 \mathrm{mmol} / \mathrm{g}$. Higher dye: AFC ratio, increased chances of interaction between adsorbate and adsorbent molecules and enhanced dye uptake. A similar phenomenon was observed during adsorption of acid dyes on chitosan (Wong et al. 2003).

Table 4 Comparison of AFC-silica with chitosan based adsorbents for adsorption of methyl orange (MO) dye

\begin{tabular}{|c|c|c|c|c|c|c|c|}
\hline Adsorbent & $\begin{array}{l}\text { Dose of } \\
\text { adsorbent }(\mathrm{g} / \mathrm{L})\end{array}$ & $\mathrm{pH}$ & $\begin{array}{l}\text { Contact time } \\
(\min )\end{array}$ & $\begin{array}{l}\text { Initial dye } \\
\text { concentration }(\mathrm{mg} / \mathrm{L})\end{array}$ & $\begin{array}{l}\text { Removal } \\
(\%)\end{array}$ & $\begin{array}{l}\text { Uptake } \\
(\mathrm{mg} / \mathrm{g})\end{array}$ & References \\
\hline AFC-silica & 6 & 3 & 400 & 100 & 33.65 & 4.26 & Present study \\
\hline $\begin{array}{l}\mathrm{Zr}(\mathrm{IV}) \text { immobilized chitosan- } \\
\text { bentonite composite }\end{array}$ & 6 & 3 & 400 & 100 & 99 & 16.5 & $\begin{array}{l}\text { Zhang et al. } \\
\text { (2015) }\end{array}$ \\
\hline AFC-silica & 8 & 6 & 100 & 20 & 42.07 & 1.1 & Present study \\
\hline Chitosan-alumina composite & 8 & 6 & 100 & 20 & 99.52 & 2.48 & $\begin{array}{l}\text { Zhang et al. } \\
\text { (2012) }\end{array}$ \\
\hline
\end{tabular}




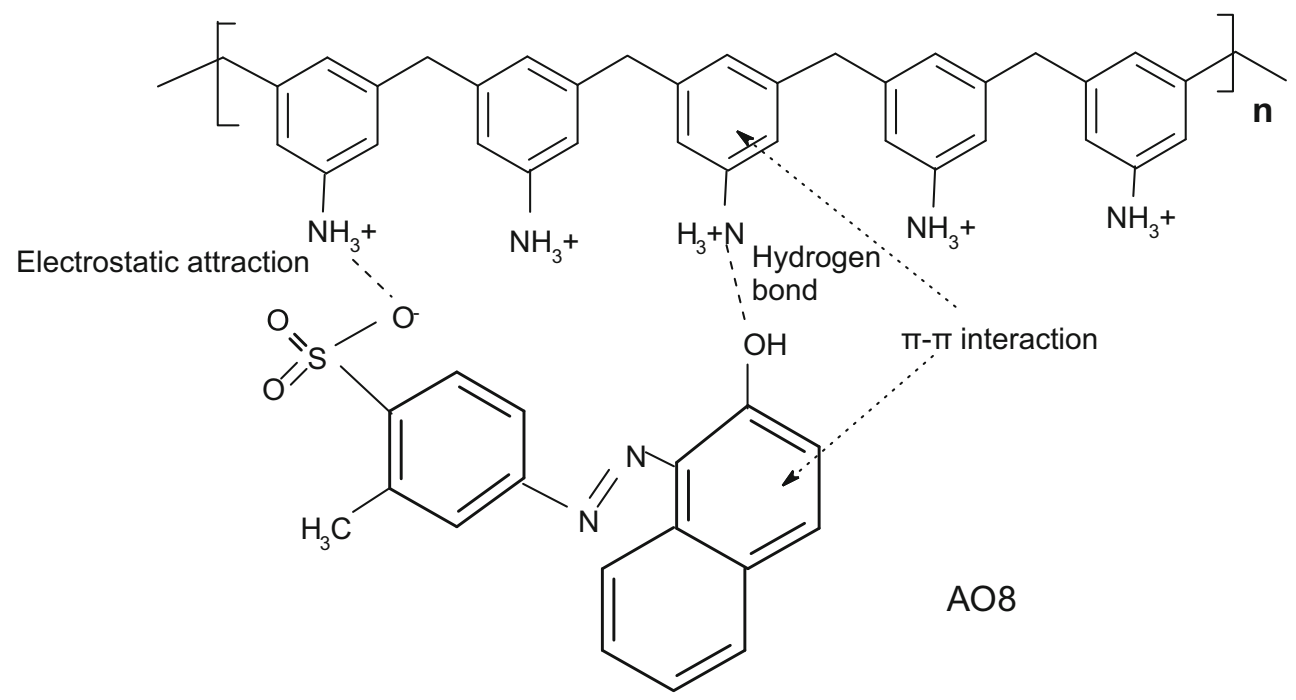

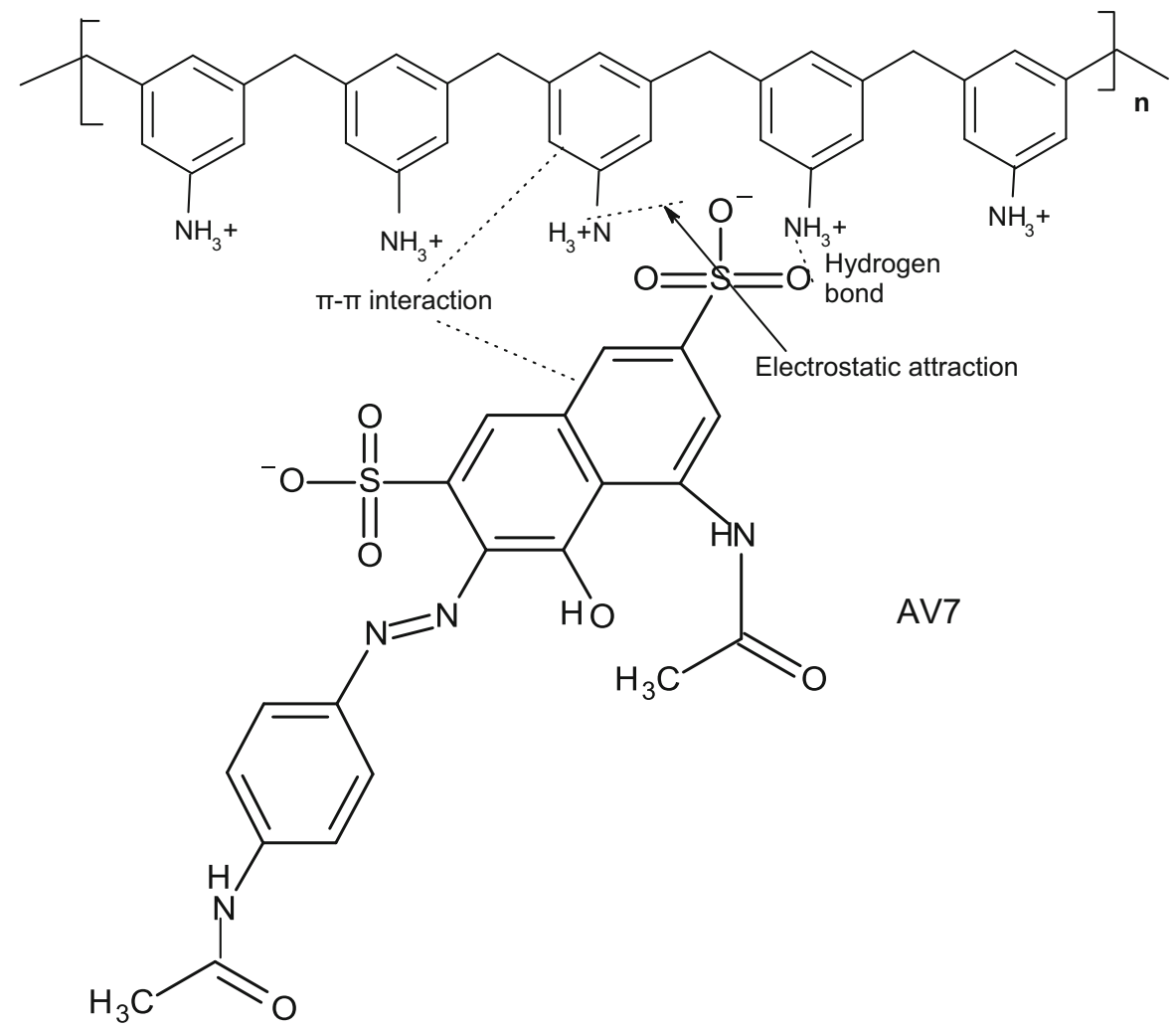

Fig. 11 Dye removal mechanism by AFC

\section{Conclusion}

Adsorption kinetics, thermodynamics and equilibrium behavior of two acid azo dyes (Acid orange 8 and Acid violet 7) on amine based polymer, named aniline formaldehyde condensate (AFC) were studied. Adsorption of both dyes was favored in acidic $\mathrm{pH}$. Electrostatic attraction with protonated amine group of AFC and hydrophobic-hydrophobic interaction and hydrogen bonding were responsible for dye uptake. AO8 adsorption isotherm was of Type I and followed Langmuir model. Adsorption isotherm of AV7 was of Type III and it followed Freundlich model. External mass transfer controlled dye adsorption on AFC. Maximum adsorption capacities of AO8 and AV7 were observed as 164 and $68 \mathrm{mg} / \mathrm{g}$, respectively. Higher molecular weight of divalent AV7 dye was responsible for lower dye: AFC ratio in solution, resulting lower uptake of AV7. 
Acknowledgements Corresponding author would like to thank Council of Scientific and Industrial Research (CSIR), Govt. of India [No. 01(2510)/11/EMR-II] for financial support to this research work. Authors are thankful to Professor Manabendra Ray, Department of Chemistry, Indian Institute of Technology Guwahati for his help and suggestions in writing the manuscript.

Open Access This article is distributed under the terms of the Creative Commons Attribution 4.0 International License (http:// creativecommons.org/licenses/by/4.0/), which permits unrestricted use, distribution, and reproduction in any medium, provided you give appropriate credit to the original author(s) and the source, provide a link to the Creative Commons license, and indicate if changes were made.

\section{References}

Ahmad R, Kumar R (2010) Conducting polyaniline/iron oxide composite: a novel adsorbent for the removal of Amido black 10B. J Chem Eng Data 55:3489-3493

Central pollution Control Board (2000). Comprehensive Industry Documents Series on Textile Industry, COINDS-59/1999-2000, India

Chiou M, Ho P, Li H (2004) Adsorption of anionic dyes in acid solutions using chemically cross-linked chitosan beads. Dyes and Pigments 60:69-84

Donia A, Atia AA, Al-amrani WA, Ei-Nahas AM (2009) Effect of structural properties of acid dyes on their adsorption behaviour from aqueous solutions by amine modified silica. J Hazard Mater $161: 1544-1550$

Elwakeel KZ, El-Ghaffar MAA, El-kousy SM, El-Shorbagy HG (2012) Synthesis of new ammonium chitosan derivatives and their application for dye removal from aqueous media. Chem Eng J 203:458-468

Elwakeel KZ, El-Bindary AA, El-Sonbatib AZ, Hawas AR (2016a) Adsorption of toxic acidic dye from aqueous solution onto diethylenetriamine functionalized magnetic glycidyl methacrylate- $N, N^{\prime}$-methylenebisacrylamide. RSC Adv 6:3350-3361

Elwakeel KZ, El-Kousy S, El-Shorbagy HG, Abd El-Ghaffard MA (2016b) Comparison between the removal of Reactive Black 5 from aqueous solutions by 3-amino-1,2,4 triazole,5-thiol and melamine grafted chitosan prepared through four different routes. J Environ Chem Eng 4:733-745

Fiol N, Villaescusa E (2009) Determination of sorbent point zero charge: usefulness in sorption studies. Environ Chem Lett 7:79-84

Foo KY, Hameed BH (2010) Insights into the modeling of adsorption isotherm systems. Chem Eng J 156:2-10

Giles CH, Smith D, Huitson A (1974a) A general treatment and classification of the solute adsorption isotherm. I: theoretical. J Colloid Interface Sci 47:755-765

Giles CH, Silva AP, Easton IA (1974b) A general treatment and classification of the solute adsorption isotherm. Part II: experimental interpretation. J Colloid Interface Sci 47(3):766-778

Girods P, Dufour A, Fierro V, Rogaume Y, Rogaume C, Zoulalin A, Celzard A (2009) Activated carbons prepared from wood particleboard wastes: characterisation and phenol adsorption capacities. J Hazard Mater 166:491-501

Gupta VK, Suhas (2009) Application of low-cost adsorbents for dye removal-a review. J Environ Manag 90:2313-2342

Hinz C (2001) Description of sorption data with isotherm equations. Geoderma 99:225-243
Kumar PA, Ray M, Chakraborty S (2007a) Hexavalent chromium removal from wastewater using aniline formaldehyde condensate coated silica gel. J Hazard Mater 143:24-32

Kumar GP, Kumar PA, Chakraborty S, Ray M (2007b) Uptake and desorption of copper ion using functionalized polymer coated silica gel in aqueous environment. Sep Purif Technol 57:47-56

Kumar PA, Chakraborty S, Ray M (2009) Adsorption behavior of trivalent chromium on amine based polymer aniline formaldehyde condensate. Chem Eng J 149:340-347

Liu Q, Yang B, Zhang L, Huang R (2015) Adsorption of an anionic azo dye by cross-linked chitosan/bentonitecomposite. Int $\mathrm{J}$ Biol Macromol 72:1129-1135

Mahanta D, Madras G, Radhakrishnan S, Patil S (2009) Adsorption and desorption kinetics of anionic dyes on doped polyaniline. J Phys Chem B 113:2293-2299

Mansour HB, Corroler D, Barillier D, Ghedira K, Chekir L, Mosrati R (2007) Evaluation of genotoxicity and pro-oxidant effect of the azo dyes: acids yellow 17, violet 7 and orange 52, and of their degradation products by Pseudomonas putida $\mathrm{mt}-2$. Food Chem Toxicol 45(1670): 1677

Mohan D, Singh KP (2002) Single- and multi-component adsorption of cadmium and zinc using activated carbon derived from bagasse-an agricultural waste. Water Res 36:2304-2318

Moussavi G, Mahmoudi M (2009) Removal of azo and anthraquinone reactive dyes from industrial wastewaters using $\mathrm{MgO}$ nanoparticles. J Hazard Mater 168:806-812

Qin Q, Ma J, Liu K (2009) Adsorption of anionic dyes on ammoniumfunctionalized MCM-41. J Hazard Mater 162:133-139

Reichenberg D (1953) Properties of ion-exchange resins in relation to their structure. III. Kinetics of exchange. J Am Chem Soc 75:589-597

Robinson T, McMullan G, Marchant R, Nigam P (2001) Remediation of dyes in textile effluent: a critical review on current treatment technologies with a proposed alternative. Biores Technol $77: 247-255$

Saha TK, Karmaker S, Ichikawa H, Fukumori Y (2005) Mechanism and kinetics of trisodium 2-hydroxy-1, $1^{\prime}$-azonaphthalene- $3,4^{\prime}, 6$ trisulfonate adsorption onto chitosan. J Colloid Interface Sci 286:433-439

Sing KSW, Everett DH, Haul RAW, Moscou L, Pierotti RA, Rouquérol J, Siemieniewska T (1985) Reporting physisorption data for gas/solid systems with special reference to the determination of surface area and porosity. Pure Appl Chem 57:603-619

Tunc S, Duman O, Gurkan T (2013) Monitoring the decolorization of Acid Orange 8 and Acid Red 44 from aqueous solution using Fenton's reagents by online spectrophotometric method: effect of operation parameters and kinetic study. Ind Eng Chem Res 52:1414-1425

Weber WJ, Morris JC (1963) Kinetics of adsorption on carbon from solutions. J Sanit Eng Div Am Soc Civ Eng 89:31-60

Wong YC, Szeto YS, Cheung WH, McKay G (2003) Equilibrium studies for acid dye adsorption onto chitosan. Langmuir 19:7888-7894

Yang H, Feng Q (2010) Characterization of pore-expanded aminofunctionalized mesoporous silicas directly synthesized with dimethyldodecylamine and its application for decolorization of sulphonated azo dyes. J Hazard Mater 180:106-114

Zhang J, Zhou Q, Ou L (2012) Kinetic, isotherm, and thermodynamic studies of the adsorption of methyl orange from aqueous solution by chitosan/alumina composite. J Enviorn Eng Data 57:412-419

Zhang L, Hu P, Wang J, Liu Q, Huang R (2015) Adsorption of methyl orange (MO) by $\mathrm{Zr}$ (IV)-immobilized cross-linked chitosan/ bentonite composite. Int J Biol Macromol 81:818-827

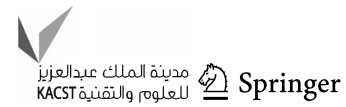

